\title{
Erratum: Lessons from sexual and reproductive health voucher program design and function: a comprehensive review
}

\author{
Corinne Grainger ${ }^{1}$, Anna Gorter ${ }^{2}$, Jerry Okal ${ }^{3^{*}}$ and Ben Bellows ${ }^{3}$
}

In the final version of our article entitled, " Lessons from sexual and reproductive health voucher program design and function: a comprehensive review" the authors inadvertently failed to acknowledge the role of International Union of Scientific Study of Population (IUSSP). IUSSP colleagues kindly reviewed early drafts of the manuscript presented at an IUSSP workshop in Bangkok August 2012 and had specifically requested that we recognize their feedback. We therefore feel obliged to acknowledge IUSSP.

\section{Acknowledgements}

The authors gratefully acknowledge comments and suggestions on the working paper from participants at the 2012 Bangkok seminar "Increasing Use of Reproductive Health Services through Community-based and Health Care Financing Programmes: Impact and Sustainability", organized by the International Union of Scientific Study of Population (IUSSP) Scientific Panel on Reproductive Health and the Institute for Population and Social Research, Mahidol University.

\section{Author details}

'Options Consultancy Services Ltd., Senior Technical Specialist, Devon House, 58 St Katharine's Way, London E1W 1LB, UK. ${ }^{2}$ Instituto CentroAmericano de la Salud, Epidemiology, Managua, Nicaragua. ${ }^{3}$ Population Council, Ralph

Bunche Rd, PO Box 17643-00500, Nairobi, Kenya.

Received: 9 January 2015 Accepted: 9 January 2015

Published online: 17 February 2015

\section{Reference}

1. Grainger C, Gorter A, Okal J, Bellows B. Lessons from sexual and reproductive health voucher program design and function: a comprehensive review. Int J Equity Health. 2014;13:33.

\footnotetext{
* Correspondence: jokal@popcouncil.org

${ }^{3}$ Population Council, Ralph Bunche Rd, PO Box 17643-00500, Nairobi, Kenya
} 